\title{
Some ethological aspects of the trophobiotic interrelations between ants (Hymenoptera: Formicidae) and larvae of the sawfly Blasticotoma filiceti (Hymenoptera: Blasticotomidae)
}

\author{
Tatiana A. NOVGORODOVA and Olga B. BIRYUKOVA \\ Institute of Systematics and Ecology of Animals, Siberian Branch of the Russian Academy of Sciences, Frunze str. 11, \\ Novosibirsk 630091, Russia; e-mail: tanovg@yandex.ru, Olya-bir@mail.ru
}

Key words. Hymenoptera, Formicidae, Formica polyctena, F. fusca, Myrmica rubra, M. ruginodis, Lasius platythorax, Camponotus sp., Blasticotomidae, Blasticotoma filiceti, behaviour, ants, trophobiosis, sawfly larvae, Siberia, Altai, Novosibirsk

\begin{abstract}
Some ethological aspects of the interrelations between ants and the larvae of Blasticotoma filiceti Klug, 1834 were investigated in the Altai Republic and Novosibirsk Region in 2006-2008. The interactions of ants with the larvae of this sawfly are determined by the concealed way of life style of $B$. filiceti. The majority of the ant-sawfly encounters occurred near holes in fern fronds at the moment when larvae excreted liquid or left their tunnels before descending to the soil prior to overwintering. Sawfly larvae visited by more aggressive ants, such as Formica s. str., leave the fern fronds slowly, which enables them to avoid inciting attacks by ants. The behaviour of the ants while collecting the larval excretion is similar to their behaviour at sugar troughs. The organisation of the collecting larval excreta by ants was investigated in detail in the cases of Formica polyctena Förster, 1850 and Myrmica rubra Linnaeus, 1758. The individual fern plants with sawfly larvae are attended by relatively constant groups of foragers in both cases. However, the highly social red wood ants interact with sawfly larvae in a more complex way. While the working groups of $M$. rubra tending sawfly larvae consist only of non-aggressive "unspecialized" foragers, those of $F$. polyctena include also a few "on duty" ants that protect the trophobionts, at least from the other ants.
\end{abstract}

\section{INTRODUCTION}

Trophobiotic interrelations with different insects are widespread among ants. The ants collect the sweet excreta of their symbionts and in exchange protect them from natural enemies (Nixon, 1951; Hölldobler \& Wilson, 1990). So far ants are thought to have mutualistic relationships with insects of only two orders: Lepidoptera (Maschwitz et al., 1987; Pierce et al., 2002) and Hemiptera, including insects of three suborders: Sternorrhyncha (aphids, scale insects, white flies), Auchenorrhyncha (leafhoppers, planthoppers) (Delabie, 2001) and Heteroptera (true bugs) (Gibernau \& Dejean, 2001; Waldkircher et al., 2004). A new type of trophobiosis between ants and larvae of the sawfly Blasticotoma filiceti Klug, 1834 (Hymenoptera: Blasticotomidae) was recently discovered (Biryukova et al., 2006; Shcherbakov, 2006). This ant-sawfly larva interaction is unique because, unlike other symbionts of ants, the sawfly larvae live inside fern fronds and are concealed from the ants for most of the time (Fig. 1). The biology of B. filiceti has been studied in detail (Meijere, 1911). The larvae of $B$. filiceti develop from eggs deposited by the imago inside fern fronds, which develop a dark colour in the places where the larvae are located. The sawfly larvae develop in short tunnels that are equal in length or slightly longer than their own length. They feed mostly on plant sap extending their tunnels forwards as they grow (Shcherbakov, 2006). The larvae make holes in the fern fronds to enable them to breathe and excrete. The diameter of the holes are increased both by the activity of the larvae from inside and the nibbling of the ferns by ants from outside (Biryukova \& Novgorodova, 2008). The older larvae leave their tunnels and descend to the soil prior to overwintering.

Species of at least two subfamilies of ants, the Formicinae and Myrmicinae, interact with this symbiont (Biryukova, 2007; Biryukova \& Novgorodova, 2008). However almost nothing is known about the behavioural aspects of the ant-sawfly larva interaction. The aim of this work is to investigate the ethological aspects of the interrelations between ants and the larvae of $B$. filiceti that remain hidden from any contact with ants for most of the time and determine whether ant-sawfly larva interactions differ depending on the species of ant.

\section{MATERIAL AND METHODS}

\section{Sites investigated}

Investigations were carried out in 2006-2008 in Siberia in coniferous forests in the North-eastern Altai (north end of Lake Teletskoe, $51^{\circ} 48^{\prime} \mathrm{N}, 87^{\circ} 17^{\prime} \mathrm{E}$, alt. $434 \mathrm{~m}$ a.s.l.) and in mixed pine and birch-aspen forests in the Novosibirsk Region $\left(54^{\circ} 57^{\prime} \mathrm{N}, 83^{\circ} 06^{\prime} \mathrm{E}\right.$, alt. $200 \mathrm{~m}$ a.s.1.). Four sites were chosen for detailed investigation, two in the Altai and two near Novosibirsk.

Trophobiotic interrelations between ants and sawfly larvae

Censuses of the trophobiotic interrelations between ants and larvae of $B$. filiceti were carried out several times during the season, from May until the end of September. In order to simplify the search for sawfly larvae and not to disturb them, they were located by searching for the following signs indicating the presence of larvae (Biryukova \& Novgorodova, 2008): frond is 
TABLE 1. The scale of aggression used when scoring the responses of ants to the irritant.

\begin{tabular}{cll}
\hline Level & $\begin{array}{c}\text { The type of ant reaction to } \\
\text { the irritant (needle) }\end{array}$ & Ant behaviour \\
\hline 0 & Avoidance & Leap down or run away \\
1 & Tolerance & Neutral reaction (ants do not react) \\
2 & Investigation & Investigate the irritant using their antennae (intense antennation) \\
3 & Adopt "An alert pose" & Stand still with mandibles slightly open and antennae slightly extended towards the irritant \\
4 & Adopt an aggressive pose & The pose adopted before an attack in which they spray acid \\
5 & Jerking of the body & Usually repeated rapid forward-and-back jerking with open mandibles, without any contact \\
6 & "Hit-and-run attack" & with the irritant \\
7 & Bite & Sudden attack of the irritant \\
8 & The "death grip" & Bite the irritant \\
& & A prolonged biting/stinging fight (ant seizes the irritant and does not loosen its grip) \\
\hline
\end{tabular}

discoloured and holed, larval excretory products on the fronds (liquid, solid, frothy) and the presence of ants (Fig. 1). Dissections of fern fronds have shown that nearly all the sites on fronds showing signs indicating the presence of larvae (presumably larvae of $B$. filiceti) contain tunnels constructed by the larvae of this sawfly (correlation about 0.99-1) (Biryukova \& Novgorodova, 2008). The typical signs of habitation by B. filiceti larvae, the number per frond and the presence of ants were recorded. Ants attending sawfly larvae were collected and fixed in $70 \%$ alcohol.

\section{Behaviour of ants attending sawfly larvae}

Visual observations on insect behaviour were carried out on the fern plants (Athyrium filix-femina (L.) Roth, 1799, Dryopteris carthusiana (Vill.) H.P., 1959, Matteuccia struthiopteris (L.) Tod., 1966) that contained larvae tended by different species of ants from July to September.

For the detailed investigation of the behaviour of ants during their interaction with sawfly larvae, two ant species were selected: Formica polyctena Förster, 1850, a species that dominates in multispecies ant communities and Myrmica rubra Linnaeus, 1758 . F . polyctena usually live in large colonies and possess large protected feeding territories. M. rubra live in small colonies and do not protect their feeding sites. One colony of each ant species was studied. Description of the anthill and foraging territory of the $F$. polyctena colony is as follows: diameter (d/D) $140 / 230 \mathrm{~cm}$, height $(\mathrm{h} / \mathrm{H}) 70 / 105 \mathrm{~cm}, 10$ foraging trails, a feeding area of about $5000 \mathrm{~m}^{2}$. The number of ants in a colony of M. rubra is about 800-1000. The behaviour of ants collecting larval excreta was observed on plants of Athyrium filix-femina tended by $F$. polyctena (5 plants) and M. rubra (1).

Visual observations were aided by marking the ants with nitro paints. Various combinations of dots of different colours were painted on the abdomen, thorax and head of ants. About 425 individuals of $F$. polyctena and 220 of M. rubra were individually marked. The behaviour of the ants attending sawfly larvae was observed in detail for $73 \mathrm{~F}$. polyctena and $19 \mathrm{M}$. rubra. Ten features of the behaviour and interaction of ants with sawfly larvae were recorded: (1) collection of larval excreta, (2) standing still, (3) trophallaxis, (4) grooming, (5) allogrooming, (6) aggressive behaviour (which includes alert poses, aggressive poses, body jerking, "hit-and-run attacks", biting and the "death grip"), (7) exploratory activity, (8) antennal contacts between ants, (9) leaving the plant with trophobionts, (10) returning to the plant with trophobionts. Time spent by ants exhibiting behavioural features 1 to 8 was recorded. In addition, the time when ants left and returned to a plant was recorded. Visual observations on the behaviour of ants leaving a plant swollen with honeydew showed that all of them went to the nest and then returned without honeydew. So, in the time budgets the period of time between leaving and returning to the plant was categorized as the time taken to transport food to the nest. The total period of time spent observing ants was about $100 \mathrm{~h}$. The time spent observing fern plants with larvae ranged from 5 to 30 h.

In order to quantify the aggressiveness of the ants, a universal scale of ant aggressiveness was developed based on data obtained from several years of investigations on the behaviour of different ants (Formica, Myrmica, Camponotus and Lasius). The scale of aggression was based on the reactions of ants to different irritants (Table 1). The reactions of each ant to an artificial irritant were recorded several times in natural, quiet conditions. A dissecting needle was used as the artificial irritant and was positioned about $1 \mathrm{~cm}$ from an ant.

\section{Data analysis}

The time budgets of the different species of ants were compared using hierarchical cluster analysis (1-Pearson $\mathrm{r}$, complete linkage). The time budgets of the ants in the different groups were compared by means of Spearman Rank correlation $\left(\mathrm{r}_{\mathrm{s}}\right)$. The proportions of time spent by the ants on a fern and their aggressiveness were compared by means of the Mann-Whitney $\mathrm{U}$ Test. The data were analyzed using STATISTICA (version 5.5) and Microsoft Excel 2003.

\section{RESULTS}

\section{The ethological peculiarities of the ant-sawfly larva interactions}

The first interactions of ants with sawfly larvae were recorded in the middle of July, both in the Altai and around Novosibirsk, which is when the sawfly larvae make holes in the fronds. It is only at this moment that trophobiotic interactions between ants and sawfly larvae become possible. The interactions of ants with sawfly larvae are determined by the concealed way of life of $B$. filiceti. Observations have shown that ants either collect the liquid excreta of a larva at the moment of excretion or they scrape dried drops of excreta off the plant (Fig. 1). The moment of excretion is easily seen as liquid appears in a hole and it seems that the whole tunnel is filled with liquid. At that moment ants usually gather around the hole, fill their crops with liquid and then transport it to their nest.

Sawfly larvae appear to be able to keep drops of liquid excreta for some time by means of special morphological structures situated at the end of their abdomen (Fig. 2). The last abdominal segment is slightly concave and is bordered by sclerotized structures similar to the structures on the distal abdominal segments of bark beetles and 


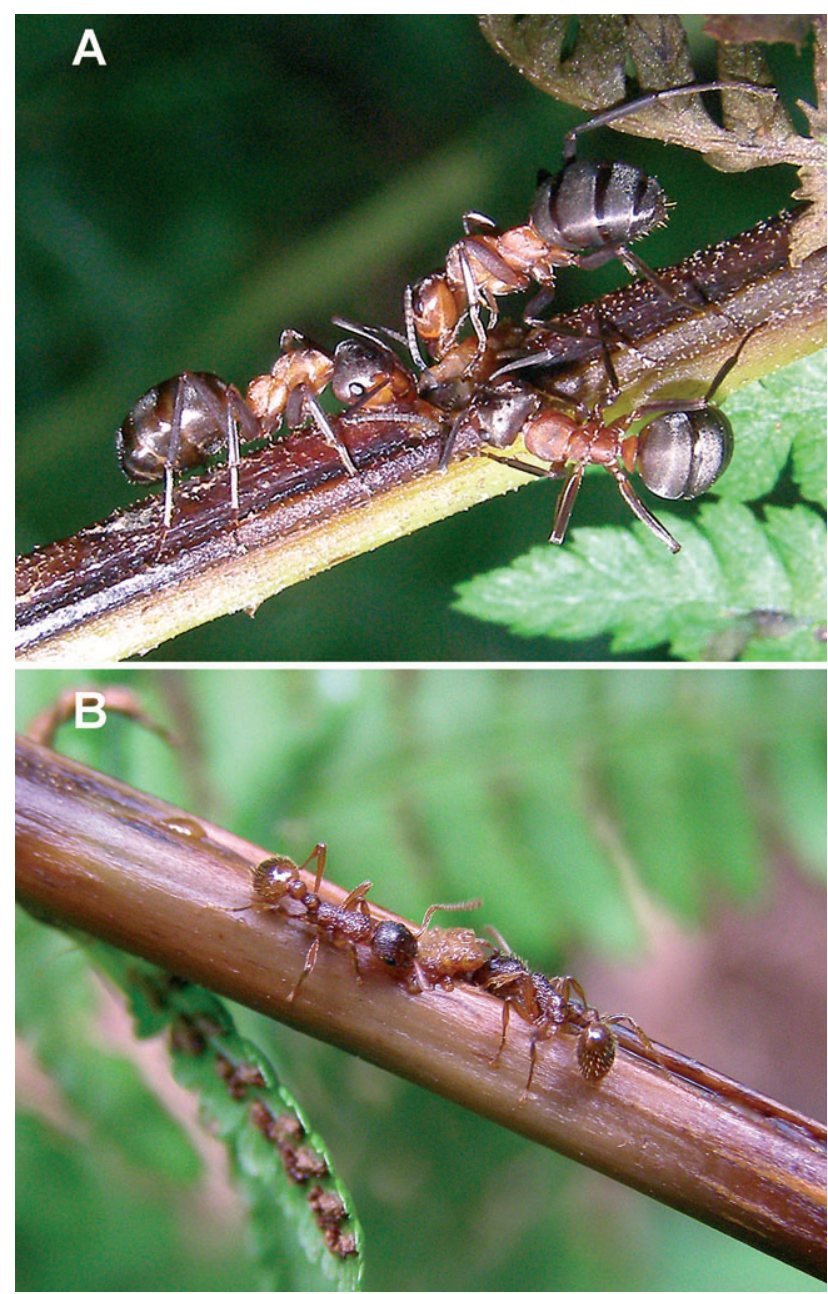

Fig. 1. Trophobioses between different ants and larvae of the sawfly Blasticotoma filiceti. A - Formica polyctena Först.; B Myrmica rubra L. (photo by T.A. Novgorodova).

some other hylotomous beetles. It is probably an adaptation for ejecting excretory products from tunnels. In addition, there are two pairs of soft processes at the apex of the abdomen. Their function is unknown, but they are probably also involved in the formation and ejection of excreta and interaction with ants when the larvae leave their tunnels in fern fronds.

As sawfly larvae are concealed from the ants inside fern fronds for most the time, the majority of the ant-sawfly contacts occur near the holes in the fern fronds or when the larvae leave their tunnels prior to descending to the soil to overwinter.

Observations on the ant-larva interactions have shown that the process by which a sawfly larva descends to the soil for overwintering is not simple. The B. filiceti larvae tended by red wood ants ( $F$. polyctena and Formica truncorum Fabricius, 1804) very slowly leave a frond prior to descending to the soil. When a larva begins to emerge from its tunnel it is the last 1-2 segments of the larva's abdomen that first appear in the aperture. This process is repeated several times and initially the larva avoids anything that touches its body, including the gentle touch of an ant's antennae. Some time later (20-45 min), several

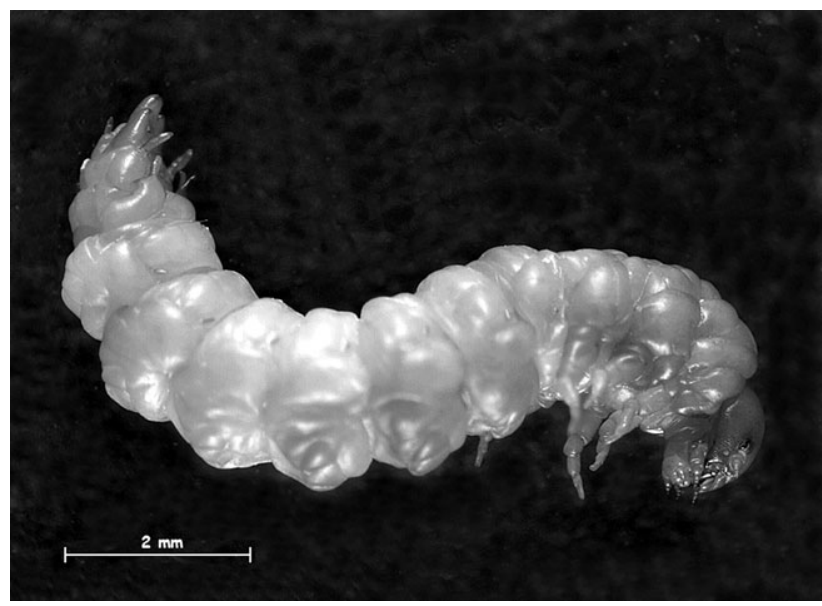

Fig. 2. The larva of the fern sawfly (photo by O.B. Biryukova).

segments (up to half the length of the abdomen) of the larva emerge for a longer period of time (3-120 s). Nineteen larvae of $B$. filiceti showed this response: 17 were tended by $F$. polyctena and 2 by $F$. truncorum.

As for the ants, they usually clean themselves after first contacting a larva. During following contacts, the behaviour of the ants resembles the way in which they tend aphids. They actively stroke the larva with their antennae. However, B. filiceti larvae usually don't produce any excretory products at this time. So the ants scrape off the remains of liquid excretory from the surface of the abdomens of the larvae (Fig. 3). Some 4-24 h after they first emerge from their tunnels, larvae usually leave the frond by dropping down and then burrowing into the ground litter.

Ants of different species do not usually meet on the same fronds at the same time. However, there are exceptions. One is Formica fusca Linnaeus, 1758 ants, which were noted on plants with larvae attended by Myrmica, Formica and Lasius ants. F. fusca ants usually collected larval excreta when the other ants were at some distance

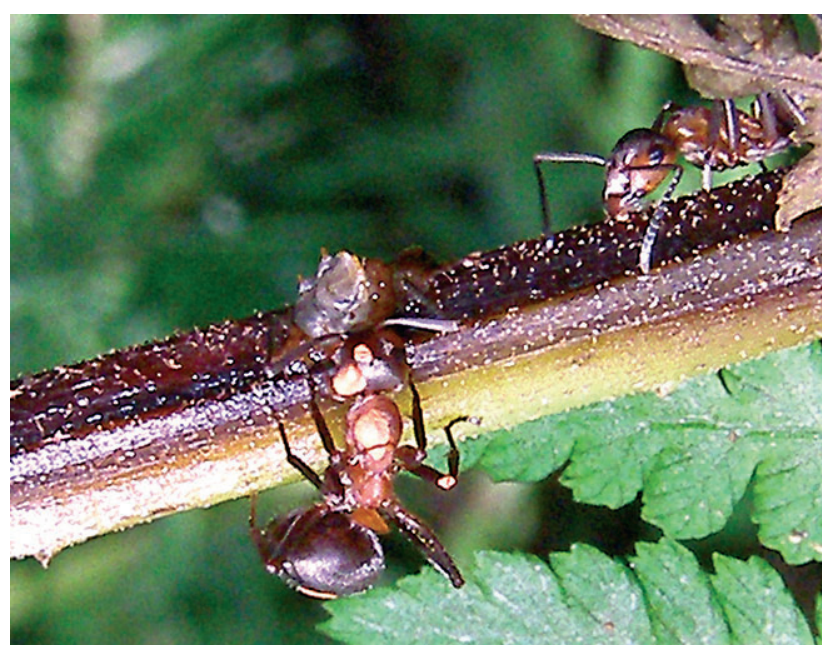

Fig. 3. The interaction between $F$. polyctena ants and a Blasticotoma filiceti larva emerging from a fern frond (photo by T.A. Novgorodova). 


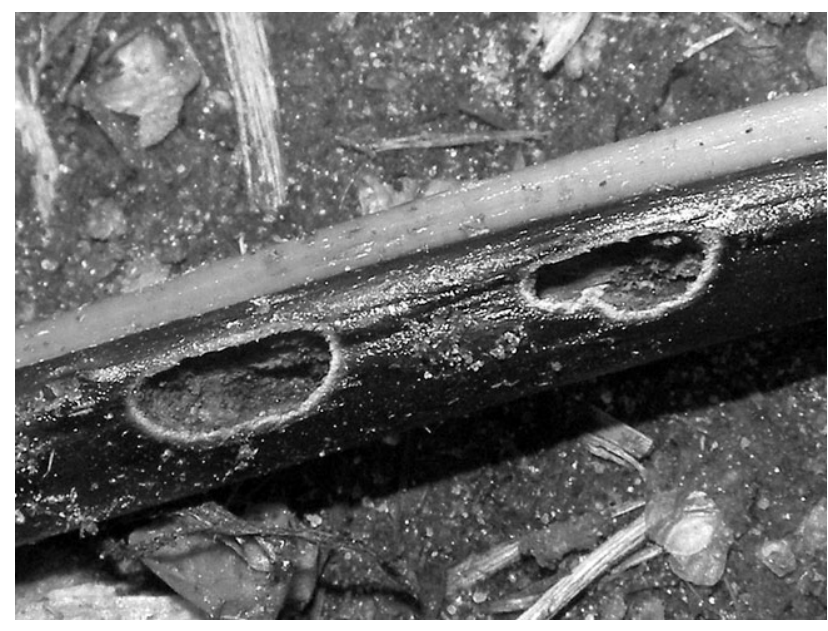

Fig. 4. Tunnels of larvae of $B$. filiceti that have been excavated by ants (photo by O.B. Biryukova).

from the larvae. Another exception is Myrmica ants. Three cases were recorded when M. rubra and M. ruginodis Nylander, 1846 visited the same fern frond with larvae at the same time.

In addition, small ants of the genera Myrmica and Lasius were seen to visit empty sawfly tunnels in fern fronds both in the Altai and Novosibirsk regions. The ants seem to collect the remains of liquid excreta of B. filiceti, scraping them from the surface and nibbling the insides of tunnels made by larvae (Fig. 4). This type of behaviour was recorded for Myrmica ants (5.98\% of the 144 larval tunnels visited by these ants) and Lasius platythorax Seifert, 1991 ( $11.11 \%$ of 9 tunnels).

\section{The organization of the collection of sawfly larval excreta by different ants}

The individual fern plants with sawfly larvae were attended by relatively constant groups of ants. The number of foragers on a frond can reach 20 (F.polyctena) or even 30 (M. rubra) and depends on the number of $B$. filiceti larvae per frond (for $F$. polyctena: $\mathrm{r}=0.48, \mathrm{n}=$ 353, $\mathrm{p}<0.01$; for M. rubra: $\mathrm{r}=0.48, \mathrm{n}=45, \mathrm{p}<0.01$ ). The number of larvae per Lady Fern frond varied from 1 to 6 in the Altai (mean $\pm \mathrm{SD}: 2.02 \pm 1.04, \mathrm{n}=507$ ) and from 1 to 10 in the Novosibirsk Regions (mean \pm SD: $3.34 \pm 1.75, \mathrm{n}=79$ ).

The cluster analysis resulted in the graphs in Fig. 5 in which ants with similar time budgets are grouped together and accorded an appropriate name based on the main functions of the foragers in each group (Fig. 5). Cluster analysis revealed that $M$. rubra ants visiting sawfly larvae have similar time budgets (Fig. 5). Detailed analyses indicate that the groups of ants visiting sawfly larvae consist of only "unspecialized" foragers working independently. These ants collect the excreta of larvae and transport it to their nest, regularly running between the fern plant and the nest and extremely rarely encountering each other (Fig. 6). In addition, M. rubra ants are not usually aggressive and have an aggressiveness score of only $0.11 \pm 0.22$ (mean $\pm \mathrm{SD} ; \mathrm{n}=19$ ).

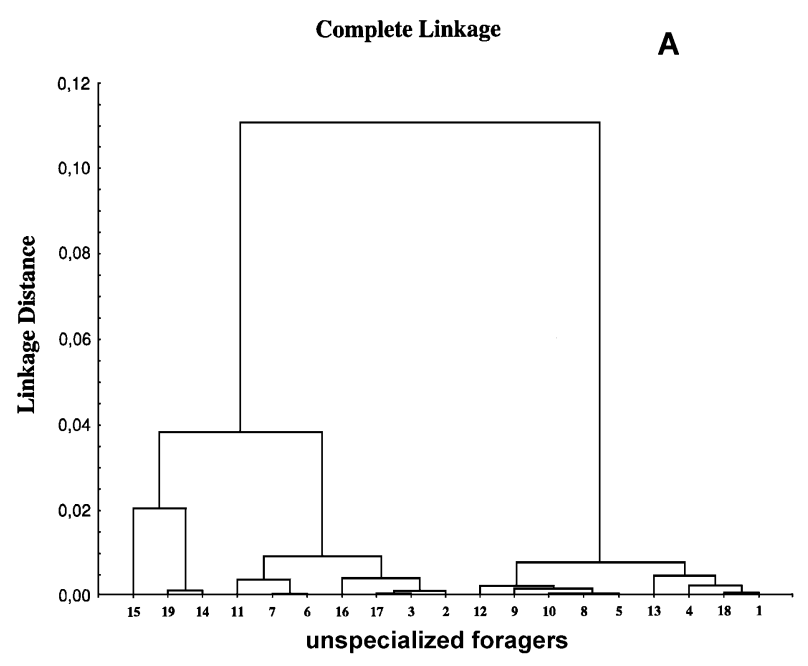

Complete Linkage

B

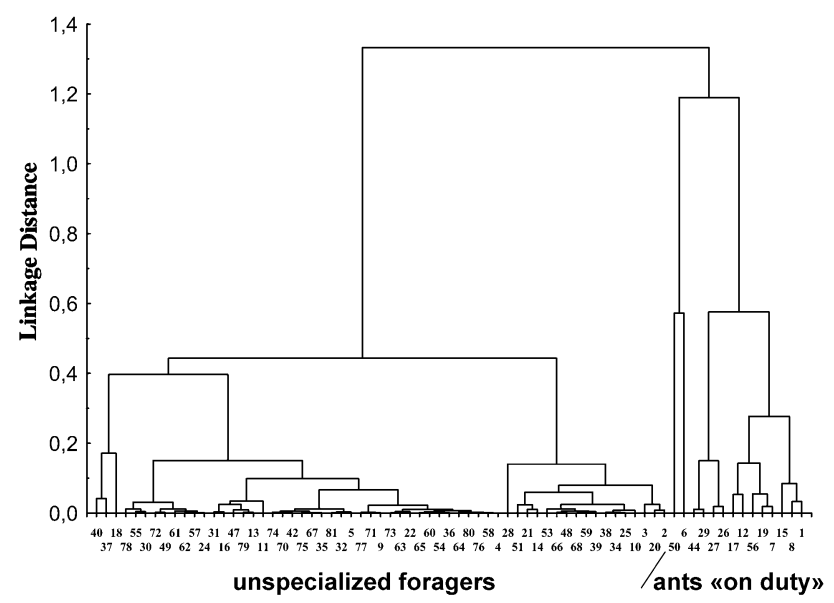

Fig. 5. Dendrograms for Myrmica rubra (A) and Formica polyctena (B) based on their correlation coefficients (1-Pearson r).

The honeydew collecting behaviour of $F$. polyctena ants, which dominate in the multispecies ant communities, is more complex. Wood ants visiting sawfly larvae are clearly divided into the following two "professional" groups: "unspecialized" foragers and ants "on duty" (Fig. 5). The average time budgets of ants in these two groups differ significantly $\left(\mathrm{r}_{\mathrm{s} \text { real }}=0.523<\mathrm{r}_{\mathrm{s} \text { critical }}=\right.$ 0.72). Most of the ants are "unspecialized" foragers (mean \pm SD: $96.85 \pm 3.74 \%, \mathrm{n}=5$ ). They collect larval excreta, rarely encounter other ants and regularly transport liquid food to the anthill (Fig. 6). Ants "on duty" make up about $5 \%($ mean \pm SD: $3.81 \pm 3.83, n=5)$ of the working ants. These ants spend significantly more time on fern plants with larvae $B$. filiceti than the "unspecialized" foragers (Fig. 7). They usually give the larval excretions they collected to "unspecialized" foragers visiting the same fern frond and very rarely left the fern. The major part of the time they collected larval excreta and explored the plant (Fig. 6). They regularly investigated fern fronds and the area around the fern, or stayed close to the hole of the larval tunnel. It is the ants "on duty" that guard sawfly larvae, at least from the other ants. In 


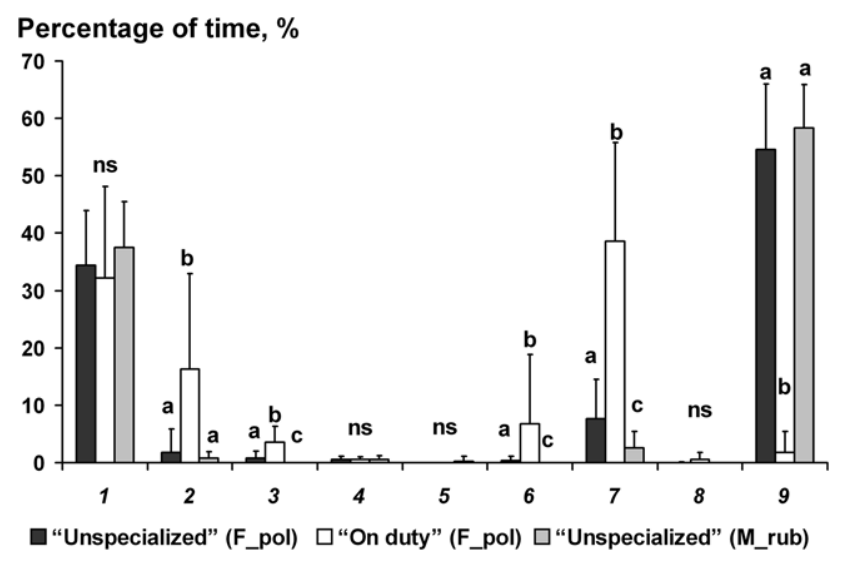

Fig. 6. The percentages of time spent by ants of Formica polyctena (F pol) and Myrmica rubra (M rub) executing different tasks: 1 - collection of larval excreta, 2 - standing still, 3 - trophallaxis, 4 - grooming, 5 - allogrooming, 6 - aggressive behaviour, 7 - exploratory activity, 8 - antennal contacts between ants, 9 - transporting food to the nest. The data for the two species showing the same behaviour marked with different letters are significantly different (Mann-Whitney U Test, $\mathrm{p}<$ $0.01)$. NS indicate no significance for pairs of data of the same behaviour.

spite of the fact that there are no significant differences between the aggressiveness of the ants "on duty" and the "unspecialized" foragers $(4.51 \pm 1.00, \mathrm{n}=14$ vs. $3.02 \pm$ $1.69, \mathrm{n}=59$; Mann-Whitney U Test, $\mathrm{p}=0.09$ ), there appears to be a pronounced tendency for ants "on duty" to be more aggressive than the "unspecialized" foragers. The "unspecialized" foragers of $F$. polyctena and $M$. rubra seem to perform similar functions. The average time budgets of these ants are similar $\left(\mathrm{r}_{\mathrm{s} \text { real }}=0.79>\mathrm{r}_{\mathrm{s} \text { critical }}\right.$ $=0.72$ ). Moreover, the percentages of time spent on ferns by ants of these groups also do not differ (Fig. 7). Significant differences were found only in the percentages of time spent by "unspecialized" foragers of $F$. polyctena and M. rubra in trophallaxis, aggressive behaviour and exploratory activity (Fig. 7).

\section{DISCUSSION}

The trophobiotic interrelations of ants with various insects have been investigated over many years (Mordvilko, 1901; Nixon, 1951; Way, 1963; Pierce et al., 2002; Novgorodova, 2004; 2008; Styrsky \& Eubanks, 2007; Oliver et al., 2008). At present the least explored type of trophobiosis is that between ants and sawfly larvae discovered quite recently in the European part of Russia (Shcherbakov, 2006), Western Siberia (Biryukova et al., 2006; Biryukova, 2007) and Germany (Liston, 2007). Sawfly larvae produce three kinds of excreta: liquid, solid and frothy (Biryukova, 2007). It is the liquid fraction that attracts ants. The solid and frothy excreta located near the holes of the larval tunnels are not collected by ants (Biryukova \& Novgorodova, 2008). It should be noted that the frothy excreta was very rarely observed in the study area (less than $1 \%$ of the larvae studied). The solid excreta was recorded only in the Altai territory.

\section{Percentage}

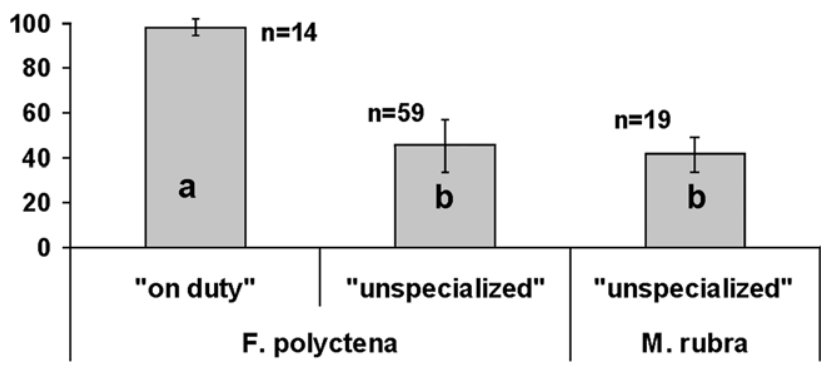

Fig. 7. The percentages of time spent by the different groups of ants on fern plants with larvae of $B$. filiceti. The data marked with different letters are significantly different (Mann-Whitney U Test, $p<0.001)$. The data marked with the same letter are not significantly different $(\mathrm{p}>0.05)$.

Liquid excreta of sawfly larvae possibly supplement the aphid honeydew collected by ants from spring (the end of April) till autumn (September-October) in this region. The excreta of sawfly larvae provide a rather important food resource for ants, at least from the middle of July until the end of August. During this period 14 species of ants belonging to 4 genera (Formica, Camponotus, Lasius, Myrmica) actively collected the excreta of sawfly larvae in this region (Biryukova \& Novgorodova, 2008). The maximum number of sawfly larvae occurred from the middle of July until the middle of August, when they begin to leave the fronds and the number of larvae decreases.

The number of ants collecting larval excreta correlated positively with the number of sawfly larvae in the fern fronds. Similar results were obtained during studies of the interactions of red wood ants with aphids (Novgorodova \& Reznikova, 1996; Novgorodova, 2008). It is known that ant-attendance correlates with the amount of honeydew produced by trophobionts (Völkl et al., 1999). The number of ants visiting sawfly larvae thus seems to depend on the amount of carbohydrate excreted by the larvae. However, some ants were found to behave like scroungers in their relations with other ants. For example, lonely foragers of $F$. fusca were observed to "steal" food from fronds containing larvae attended by other ants. Similar behaviour is recorded for Serviformica ants, which exploit aphid colonies attended by ants of other species (Novgorodova \& Reznikova, 1996).

The concealed life style of $B$. filiceti determines the interactions of ants with sawfly larvae. All the ant-sawfly encounters occur near the holes in the fern fronds at the moment when the larvae leave their tunnels or excrete liquid. The period of time when the larvae leave their tunnels in the fronds is a very dangerous time for them. It is a well known fact that ants are also predators of sawfly larvae (Verzhutskiy, 1981). In addition, four cases were recorded of $F$. polyctena ants returning to their nest with larvae. It is known that ants can associate the production of honeydew with the chemical characteristics of the cuticle of trophobionts, which suppresses ant aggression (Choe \& Rust, 2006). It is likely that the slow manner in which a larva leaves a frond assists ants to recognize it as 
a symbiont and enables the larva to avoid attacks by the ants.

As for the behaviour of the ants collecting larval excreta, it is similar to that recorded at sugar troughs. It is likely that foragers do not need to have any special skills in order to collect the excreta of B. filiceti larvae, unlike when tending aphids, which need to be solicited to produce more excreta. Nevertheless, the behaviour of ants interacting with sawfly larvae varies in its complexity. The collection of sawfly larval excreta by $F$. polyctena ants, which are dominant in multispecies ant communities, and of M. rubra from small colonies, differed. The individual fern plants with sawfly larvae are attended by relatively constant groups of ants. However the behaviour of the highly social red wood ants of $F$. polyctena recorded when interacting with sawfly larvae was more complex. While the working groups of $M$. rubra tending sawfly larvae consist only of non-aggressive "unspecialized" foragers, those of $F$. polyctena include a few ants "on duty", which protect the trophobionts, at least from the other ants.

Ants tending colonies of aphids infesting the surfaces of plants show a range of different behaviours: from unspecialized foragers to "professional" specialization with a clear division of tasks (Reznikova \& Novgorodova, 1998; Novgorodova, 2007, 2008). Red wood ants have the most complex behaviour with marked "professional" specialization, with each colony of aphids tended by a specific group of ants. Four "professional" groups of foragers with different functions were identified. The "shepherds" collect honeydew, the "guards" protect aphid colonies, the "transporters" carry honeydew to the anthill and the "scouts" (or "coordinators") search for new colonies and coordinate the group activities (Reznikova \& Novgorodova, 1998; Novgorodova, 2008). The ants "on duty" seem to be analogous to the "guards" and "shepherds" tending aphids, which also spend almost all their time tending aphid colonies. Preliminary analysis has shown that the group of $F$. polyctena ants "on duty" is not homogeneous. However, this and the differences in the behaviour of the "on duty" ants both require more detailed study.

ACKNOWLEDGEMENTS. For valuable comments on and interest in this study we are indebted to A.P. Rasnitsyn and Zh.I. Reznikova. We would also like to thank A.C. Pont (Oxford University Museum of Natural History, Oxford, UK) for improving and checking the English of this manuscript. We are grateful to anonymous reviewers for their valuable comments on the manuscript. This study was supported in part by the Russian Foundation of Basic Research (No. 09-04-00152) and Presidium of Russian Academy of Sciences (No. 26.6).

\section{REFERENCES}

BIRYUKOVA O.B. 2007: On the trophobiotic interaction of ants (Hymenoptera: Formicidae) with sawfly larvae of Blasticotomidae (Hymenoptera). Myrmecol. News 10: 101.

Biryukova O.B. \& Novgorodova T.A. 2008: Trophobiotic interactions between representatives of the order Hymenoptera: ants (Formicidae) and sawfly larvae (Blasticotomidae). Evraziat. Entomol. Zh. 7: 227-233 [in Russian, English abstr.].
Biryukova O.B., Rasnitsyn A.P. \& Novgorodova T.A. 2006: On trophobiotic interactions of ants with different insects. In: Proceedings of the VII ${ }^{\text {h }}$ Conference of Entomologists of Siberia and Far East, "Entomologic Investigations in North Asia”. Novosibirsk, pp. 203-205 [in Russian].

Choе D.-H. \& Rust M.K. 2006: Homopteran chemical signatures reduce aggression of tending ants. Chemoecology 16: $175-178$.

Delabie J.H.C. 2001: Trophobiosis between Formicidae and Hemiptera (Sternorrhyncha and Auchenorrhyncha): an overview. Neotrop. Entomol. 30: 501-516.

Gibernau M. \& Dejean A. 2001: Ant protection of a Heteropteran trophobiont against a parasitoid wasp. Oecologia 126: 53-57.

Hölldobler B. \& Wilson E.O. 1990: The Ants. Springer, Berlin, $732 \mathrm{pp}$.

Liston A.D. 2007: Zur Biologie und Vorkommen von Blasticotoma filiceti Klug, 1834 (Hymenoptera, Blasticotomidae) in Brandenburg und Berlin. Nachr. Ber. 51: 95-99.

Maschwitz U., Fiala B. \& Dolling W.R. 1987: New trophobiotic symbioses of ants with South east Asian bugs. J. Natur. History. 21: 1097-1107.

MeIJERE J.C.H. 1911: Über in Farnen parasitierende Hymenopteren- und Dipteren-Larven. Tijdschr. Entomol. 54: 80-127.

MoRDVILKO A.K. 1901: Biology and morphology of aphids. Proc. Russ. Entomol. Soc. 33: 418-475 [in Russian].

Nixon G.E.J. 1951: The Association of Ants with Aphids and Coccids. Commonwealth Institute of Entomology, London, $36 \mathrm{pp}$.

Novgorodova T.A. 2004: The symbiotic relationships between ants and aphids. Zh. Obsch. Biol. 65: 152-165 [in Russian, English abstr.].

Novgorodova T.A. 2007: The specialization in groups of ants tending aphid colonies (Hymenoptera: Formicidae; Homoptera: Aphididae). Myrmecol. News 10: 115.

Novgorodova T.A. 2008: The specialization in ant working groups involved in trophobiosis with aphids. Zh. Obsch. Biol. 69: 293-302 [in Russian, English abstr.].

Novgorodova T.A. \& Reznikova Zh.I. 1996: Ecological aspects of interaction between ants and aphids in the forest park zone of the Novosibirsk Scientific Centre. Siber. J. Ecol. (3-4): 239-245 [in Russian, English abstr.].

Oliver T.H., Leather S.R. \& CoOK J.M. 2008: Macroevolutionary patterns in the origin of mutualisms involving ants. $J$. Evol. Biol. 21: 1597-1608.

Pierce N.E., Braby M.F., Heath A., Lohman D.J., Mathew J., Rand D.B. \& Travassos M.A. 2002: The ecology and evolution of ant association in the Lycaenidae (Lepidoptera). Annu. Rev. Entomol. 47: 733-771.

Reznikova Zh.I. \& Novgorodova T.A. 1998: Division of labour and exchange of information within ant settlement. Usp. Sovrem. Biol. 118: 345-357 [in Russian, English abstr.].

ShCHERBAKov D.E. 2006: Fern sawfly larvae Blasticotoma filiceti Klug, 1834 (Hymenoptera: Blasticotomidae) are visited by ants: a new kind of trophobiosis. Russ. Entomol. J. 16: $67-72$.

STYRSKY J.D. \& EubANKS M.D. 2007: Ecological consequences of interactions between ants and honeydew-producing insects. Proc. R. Soc. (B) 274: 151-164.

VERZHUTSKIY B.N. 1981: Herbivorous Insects in Ecosystems of Eastern Siberia. Novosibirsk, 302 pp. [in Russian].

VölkL W., Woodring J., Fischer M., Lorenz M.W. \& HoffMANN K.H. 1999: Ant-aphid mutualisms: the impact of honeydew production and honeydew sugar composition on ant preferences. Oecologia 118: 483-491.

WaldKIRcher G., Webb M.D. \& Maschwitz U. 2004: Description of a new shieldbug (Heteroptera: Plataspidae) and its close association with a species of ant (Hymenoptera, Formicidae) in Southeast Asia. Tijdschr. Entomol. 147: 21-28.

WAY M.J. 1963: Mutualism between ants and honeydew producing Homoptera. Annu. Rev. Entomol. 8: 307-344.

Received May 27, 2010 revised and accepted July 8, 2010 